\title{
ESPUMA BUCAL NA REDUÇÃO DA PLACA BACTERIANA DENTAL EM CÃES
}

\author{
Viviam Pignone ${ }^{1}$ \\ Dafne Londero Cruz ${ }^{2}$ \\ Valesca Borba ${ }^{3}$ \\ Rubens Alves Pereira ${ }^{4}$ \\ Tamara Zinn Ferreira ${ }^{5}$ \\ Giulia Soares Latosinski ${ }^{5}$
}

\begin{abstract}
RESUMO
Na odontologia veterinária, os métodos de qualificação e quantificação da doença periodontal e da higiene oral têm sido utilizados para avaliação de produtos com potencial preventivo no acúmulo de cálculo dentário. Diante disso, o presente estudo teve como objetivo avaliar o uso da espuma de higienização bucal à base de própolis (Espuma Bucal IBASA ${ }^{\circledR}$ ) no retardo da formação da placa bacteriana dental em cães. Foram avaliados 17 cães conforme critérios préestabelecidos pelo Veterinary Oral Health Council (VOHC). Os animais foram submetidos à profilaxia dentária e divididos em dois grupos: Controle (CTL) e Espuma Bucal (EB), administrada uma vez ao dia, durante 30 dias. Após 30 dias, os dentes dos animais foram avaliados quanto à formação de placa a partir do índice de placa bacteriana estabelecido por Logan \& Boyce. Foi observada redução $(p=0,04)$ dos índices de placa nos dentes incisivos e caninos dos animais tratados com a EB $(1,18 \pm 0,66)$ em relação ao CTL $(2,45 \pm 0,92)$. Além disso, foi observada uma redução dos índices de placa em cães que receberam EB quando comparados com os CTL, considerando os dentes do lado esquerdo (16\%), direito (2\%), maxilares (5\%) e mandibulares (16\%). O uso da EB, além de ser de fácil aplicação, auxilia na manutenção da saúde bucal de dentes e gengivas dos animais controlando a proliferação dos micro-organismos causadores da doença bacteriana, sendo uma boa alternativa para a redução da placa dental em cães.
\end{abstract}

Palavras-chave: cães, doença periodontal, espuma bucal, índice de placa.

\section{ORAL FOAM IN REDUCING THE BACTERIAL DENTAL PLATE IN DOGS}

\begin{abstract}
In veterinary dentistry, methods of qualification and quantification of periodontal disease and oral hygiene have been used to evaluate products with preventive potential in the accumulation of calculus. Therefore, the present study aimed to evaluate the use of propolisbased oral hygiene foam (Espuma Bucal IBASA ${ }^{\circledR}$ ) in reducing plaque formation in dogs. Seventeen dogs were evaluated according to criteria established by the Veterinary Oral Health Council (VOHC). The animals were submitted to prophylaxis and divided into two groups:

\footnotetext{
${ }^{1}$ Médica Veterinária. Clínica Allpet, Porto Alegre, RS, Brasil. vividogodonto@ gmail.com

${ }^{2}$ Médica Veterinária. Gerente Técnica de Produto do Laboratório Ibasa. Porto Alegre, RS, Brasil. dafne_cruz@yahoo.com.br

${ }^{3}$ Farmacêutica Industrial. Gerente de Pesquisa e Desenvolvimento do Laboratório Ibasa. Porto Alegre, RS, Brasil.valesca.borba@hotmail.com

${ }^{4}$ Farmacêutico Industrial. Pesquisador Associado UFPEL, Pelotas, RS, Brasil. rubens_ap@yahoo.com.br

${ }^{5}$ Médica Veterinária. Setor de Pesquisa e Desenvolvimento do Laboratório Ibasa. Porto Alegre, RS, Brasil. Correspondência: giulia.latosinski@ibasa.com.br
} 
Control (CTL) and Oral Foam (EB), given once a day, for 30 days. After 30 days, the teeth of the animals were evaluated for plaque formation from the plaque index established by Logan $\&$ Boyce. Significant reduction $(\mathrm{p}=0.04)$ of the incisor and canine teeth plaque indices was observed in animals treated with EB $(1.18 \pm 0.66)$ in relation to CTL $(2.45 \pm 0.92)$. In addition, was observed a reduction in plaque rates in dogs that received EB when compared with CTL, considering left (16\%), right (2\%), maxillary (5\%) and mandibular teeth $(16 \%)$. The use of oral foam, besides being easy to apply, helps maintain the oral health of animals by controlling the proliferation of microorganisms that cause bacterial disease and being an alternative for reducing plaque in dogs.

Keywords: dogs, periodontal disease, oral foam, plaque index.

\section{ESPUMA ORAL PARA REDUCIR LA PLACA BACTERIANA DENTAL EN PERROS}

\section{RESUMEN}

En odontología veterinaria, los métodos de calificación y cuantificación de la enfermedad periodontal y la higiene bucal se han utilizado para evaluar productos con potencial preventivo en la acumulación de cálculo dental. Por lo tanto, el presente estudio tuvo como objetivo evaluar el uso de espuma de higiene oral a base de propóleos (Oral Foam IBASA ${ }^{\circledR}$ ) para retrasar la formación de placa dental en perros. Se evaluaron 17 perros de acuerdo con criterios preestablecidos por el Consejo Veterinario de Salud Oral (VOHC). Los animales fueron sometidos a profilaxis dental y divididos en dos grupos: Control (CTL) y Foam Mouth (EB), administrados una vez al día, durante 30 días. Después de 30 días, se evaluó la formación de placa en los dientes de los animales a partir del índice de placa establecido por Logan \& Boyce. Se observó una reducción $(\mathrm{p}=0.04)$ de los índices de placa en incisivos y caninos de animales tratados con EB $(1.18 \pm 0.66)$ en relación con CTL $(2.45 \pm 0.92)$. Además, se observó una reducción en los índices de placa en perros que recibieron EB en comparación con CTL, considerando los dientes de la izquierda (16\%), derecha (2\%), mandíbulas (5\%) y mandibular (16\%). El uso de EB, además de ser fácil de aplicar, ayuda a mantener la salud bucal de los dientes y las encías de los animales al controlar la proliferación de microorganismos que causan enfermedades bacterianas y es una alternativa para reducir la placa dental en los perros.

Palabras clave: perros, enfermedad periodontal, espuma oral, índice de placa.

\section{INTRODUÇÃO}

Halitose é o termo utilizado para caracterizar odores desagradáveis emitidos pelo hálito do paciente, podendo ser de origem intra ou extra-bucal (1). Na maioria dos casos, a halitose é o principal sinal clínico da Doença Periodontal (DP) que os proprietários detectam nos seus animais, sendo resultante da necrose de tecidos e da fermentação bacteriana no sulco gengival ou na bolsa periodontal (2).

Uma boa higiene oral, saúde sistêmica, dieta nutricional adequada, alimentos abrasivos que limpam mecanicamente os dentes e exercitam o ligamento periodontal e gengiva, propiciam condições saudáveis aos tecidos periodontais ao longo da vida do cão. Porém, se 
um ou mais destes fatores não estiverem em equilíbrio haverá acúmulo de placa, os tecidos serão prejudicados, resultando em DP $(3,4)$.

Ao estabelecer o plano de prevenção ou tratamento, o Médico Veterinário deve estar atento à tríade proprietário-animal-ambiente, pois fatores como custo, disponibilidade de tempo para cuidados caseiros, relação/função que o animal exerce, dieta oferecida, entre outros, irão definir que atitude o profissional deverá apresentar ao proprietário e as alternativas terapêuticas para cada caso $(5,6)$. A alta prevalência de DP em cães, assim como o risco do surgimento de doenças sistêmicas associadas, demonstra a importância deste tema $(7,8)$.

A DP é considerada a enfermidade oral mais comum em animais de companhia, podendo apresentar-se na forma de gengivite e periodontite (9). Causada pelo biofilme dentário, a sua formação inicia-se pelo acúmulo de bactérias orais com capacidade de adesão à superfície dental e é facilitada pela presença e produção de uma matriz composta de glicoproteínas salivares e polissacarídeos extracelulares (10-12).

A DP acomete o periodonto, que é composto por: gengiva, osso alveolar, cemento e ligamento periodontal. Esta doença é causada pelo acúmulo de Placa Bacteriana (PB) nos dentes e estruturas adjacentes que o suportam. Se o acúmulo de PB não for controlado, ocorre a progressão da DP $(13,14)$.

A PB é caracterizada pela aderência de bactérias orais à superfície dos dentes e o seu desenvolvimento tem início na formação de uma película composta por glicoproteínas salivares que envolvem a superfície dentária, chamada película adquirida, cuja formação ocorre 20 segundos após a erupção do dente ou limpeza dentária. Posteriormente, ocorre a aderência e colonização primária de micro-organismos à película adquirida. A produção bacteriana de polissacarídeos e outros metabólitos celulares permite a agregação de novos e diferentes micro-organismos cuja multiplicação leva à formação de biofilmes maduros em cerca de 72 horas. Estes biofilmes são constituídos por várias camadas de diversas espécies bacterianas que desenvolvem interações complexas, contribuindo para a proteção da placa. Devido aos sais de cálcio fosfatados e carbonatos presentes na saliva do cão, a PB pode ainda mineralizar formando cálculo dentário $(8,15,16)$. A formação de cálculo dentário ocorre quando estes sais presentes no fluido salivar cristalizam na superfície do dente, mineralizando a placa macia. Após 2 a 3 dias, a PB mineralizada para formar cálculos resistentes à uma limpeza rápida $(17,18)$. Em razão desta forte aderência, o cálculo dentário é removido durante o tratamento periodontal sob anestesia geral $(10,14,19)$.

Estudos sugerem que a gravidade e a incidência da doença em cães aumentam com a idade, atingindo $84 \%$ dos animais com 3 anos ou mais $(7,8,20)$. A raça também condiciona a prevalência da DP, sendo mais frequente em cães de pequeno porte e braquicefálicas. Outros fatores predisponentes agravantes da doença incluem o apinhamento dentário e a má oclusão, os quais podem resultar em fístulas e abcessos em estágios avançados da doença. Além disso, a DP pode causar efeitos sistêmicos devido ao seu tropismo por locais inflamados, podendo desenvolver endocardite bacteriana e doença renal crônica $(8,18,20,21)$.

Por ser uma doença de difícil mensuração, são utilizados índices de placa bacteriana para estabelecer os graus de DP em cães, de acordo com a área da superfície vestibular dental acometida. Assim, as avaliações específicas bucais podem ser avaliadas por meio da sua expressão clínica da doença na forma de valor numérico, permitindo a análise estatística da extensão acometida, tendo como resultado uma padronização objetiva e consistente (14).

A terapia periodontal é baseada no controle da $\mathrm{PB}$, com a realização da profilaxia dentária profissional e tratamento periodontal em casos mais avançados, incluindo extrações

Pignone V, Cruz DL, Borba V, Pereira RA, Ferreira TZ, Latosinski GS. Espuma bucal na redução da placa bacteriana dental em cães. Vet. e Zootec. 2020.; 27: 001-011. 
e/ou cirurgia periodontal. Entretanto, o fator mais importante na prevenção bucal é a escovação dental, a qual deve ser iniciada ainda quando filhotes $(18,22)$.

Estudos têm mostrado que procedimentos de higiene mecânica podem prevenir a DP em cães com sucesso. Entretanto, o nível de dedicação requerido para obter e manter a saúde oral em cães não é facilmente mantido pelos tutores $(14,23)$. Neste cenário, algumas alternativas para profilaxia periodontal têm surgido no mercado para uso doméstico, como pastas enzimáticas, ascorbato de zinco, gluconato de clorexidina, pastas e espumas bucais. Diante disso, o presente estudo teve como objetivo avaliar a redução da formação da placa bacteriana pelo uso de espuma de higienização bucal à base de própolis (Espuma Bucal IBASA ${ }^{\circledR}$ ).

\section{MATERIAL E MÉTODOS}

O projeto de estudo foi realizado conforme preconizado pelo Veterinary Oral Health Council (VOHC), órgão americano responsável pelo registro e selo de aprovação dos produtos veterinários de higiene oral que controlam ou retardam a formação de PB e cálculo dentário.

De acordo com o VOHC, recomenda-se um protocolo padrão para a realização de experimentos relacionados com PB e cálculo dentário, no qual os animais devem ter peso corporal, conformação de crânio e idade similares. A saúde geral deve ser avaliada por meio de exames e se apresentarem dentro dos padrões de normalidade. Para tal desenho experimental todos os animais devem receber uma dieta padronizada (24).

\section{Animais:}

Foram avaliados 17 cães, com idade entre 3 e 5 anos, de peso entre 5-10 kg, machos e fêmeas, saudáveis sem qualquer outra doença concomitante e mantidos com a mesma dieta balanceada (ração seca super premium). Os animais foram imunizados com as vacinas polivalente e antirrábica, controle negativo de endoparasitas e ectoparasitas. A inclusão foi de forma voluntária, com a ciência do proprietário sobre os procedimentos e com o comprometimento de seguir o protocolo estabelecido para o projeto ssinandoC um Termo de Consentimento Livre e Esclarecido (TCLE).

Os animais foram distribuídos aleatoriamente em dois grupos experimentais:

- Controle (CTL): Receberam apenas profilaxia dentária;

- Espuma Bucal (Espuma Bucal IBASA ${ }^{\circledR}$ - EB): Receberam profilaxia dentária no dia zero (T0) e 24h após iniciaram a aplicação da Espuma Bucal uma vez ao dia, durante 30 dias (T30).

\section{Índice de Placa Bacteriana (IPB):}

Previamente ao estudo, todos os cães foram submetidos à profilaxia dentária profissional com uso de ultrassom odontológico (Kavo), seguido da sondagem periodontal. $\mathrm{O}$ procedimento foi finalizado com o polimento de todos os dentes com pasta profilática em taça de borracha acoplada no contra-ângulo e micromotor (Kavo), sob anestesia inalatória e bloqueio regional. O protocolo anestésico foi instituído de acordo com cada paciente. Decorridos 30 dias da remoção do cálculo dentário, os animais foram novamente anestesiados para avaliação do IPB, segundo metodologia descrita por Logan e Boyce (25).

Para mensuração do IPB, os dentes avaliados (maxila: I3 - 103 e 203, C- 104 e 204, PM3 - 107 e 207, PM4 - 108 e 208 e M1 - 109 e 209; mandíbula: C - 304 e 404, PM3 - 307 
e 407, PM4 - 308 e 408, M1 - 309 e 409) foram divididos horizontalmente nas metades gengival e coronal e, para cada parte, foi designado um escore para a área e um para a espessura da PB (intensidade de coloração), conforme Tabela 1.

$\mathrm{O}$ escore de cada metade foi calculado multiplicando-se o escore da sua área pelo da sua espessura. Os escores gengival e coronal foram somados para se obter o escore total do dente; a soma do escore de todos os dentes foi dividida pelo número de dentes avaliados, obtendo-se o IPB do animal (25).

A PB foi avaliada utilizando o evidenciador de placa (Replak ${ }^{\circledR}$ - Dentsply, Catanduva, SP), aplicado sobre a superfície dentária com o auxílio de algodão embebido no corante, seguido da remoção do seu excesso com água em spray da seringa tríplice.

Tabela 1. Sistema de Índice de Placa Bacteriana conforme Logan e Boyce (25)

\begin{tabular}{lll}
\hline \multicolumn{3}{l}{ Escore de área da superfície dental acometida } \\
\hline 0 & Sem placa \\
1 & Menos de $25 \%$ & \\
2 & Entre 25 a $50 \%$ & \\
3 & Entre 50 a $75 \%$ \\
4 & Entre 75 a $100 \%$ & Rosa a vermelho claro \\
\hline Intensidade da coloração (espessura) & \\
\hline 1 & Amarelo claro & Vermelho \\
2 & Marrom claro & \\
3 & Marrom escuro & \\
\hline
\end{tabular}

\section{Análise Estatística:}

Os dados foram analisados utilizando-se Análise de Variância (ANOVA) sendo considerados os IPB conforme metodologia de Logan e Boyce (25). Diferenças significativas foram calculadas por meio do Teste Tukey $(\mathrm{P}<0,05)$.

\section{RESULTADOS E DISCUSSÃO}

Após 30 dias do início do estudo, os animais dos grupos CTL e EB foram avaliados quanto aos escores de PB, considerando os dentes estudados: incisivos e caninos (I3 - 103 e 203, C- 104 e 204; C - 304 e 404); pré-molares e molares (PM3 - 107 e 207, PM4 - 108 e 208 e M1 - 109 e 209; PM3 - 307 e 407, PM4 - 308 e 408, M1 - 309 e 409); dentes maxilares (I3 - 103 e 203, C- 104 e 204, PM3 - 107 e 207, PM4 - 108 e 208 e M1 - 109 e 209); dentes mandibulares (C - 304 e 404, PM3 -307 e 407, PM4 - 308 e 408, M1 - 309 e 409); dentes do lado direito (I - 103, C - 104 e 404, PM3 - 107 e 407, PM4 - 108 e 408 e M1 - 109 e 409) e dentes do lado esquerdo (I - 203, C - 204 e 304, PM3 - 207 e 307, PM4 - 208 e 308 e M1 - 209 e 309) (Figura 1 e 2).

Segundo os resultados, os animais tratados com Espuma Bucal apresentaram uma redução $(p=0.04)$ de $52 \%$ no índice de placa dos dentes incisivos e caninos quando 
comparados ao grupo controle $(2,45 \pm 0,92$ vs 1,18 $\pm 0,66$ grupos CTL e EB, respectivamente) (Tabela 2).
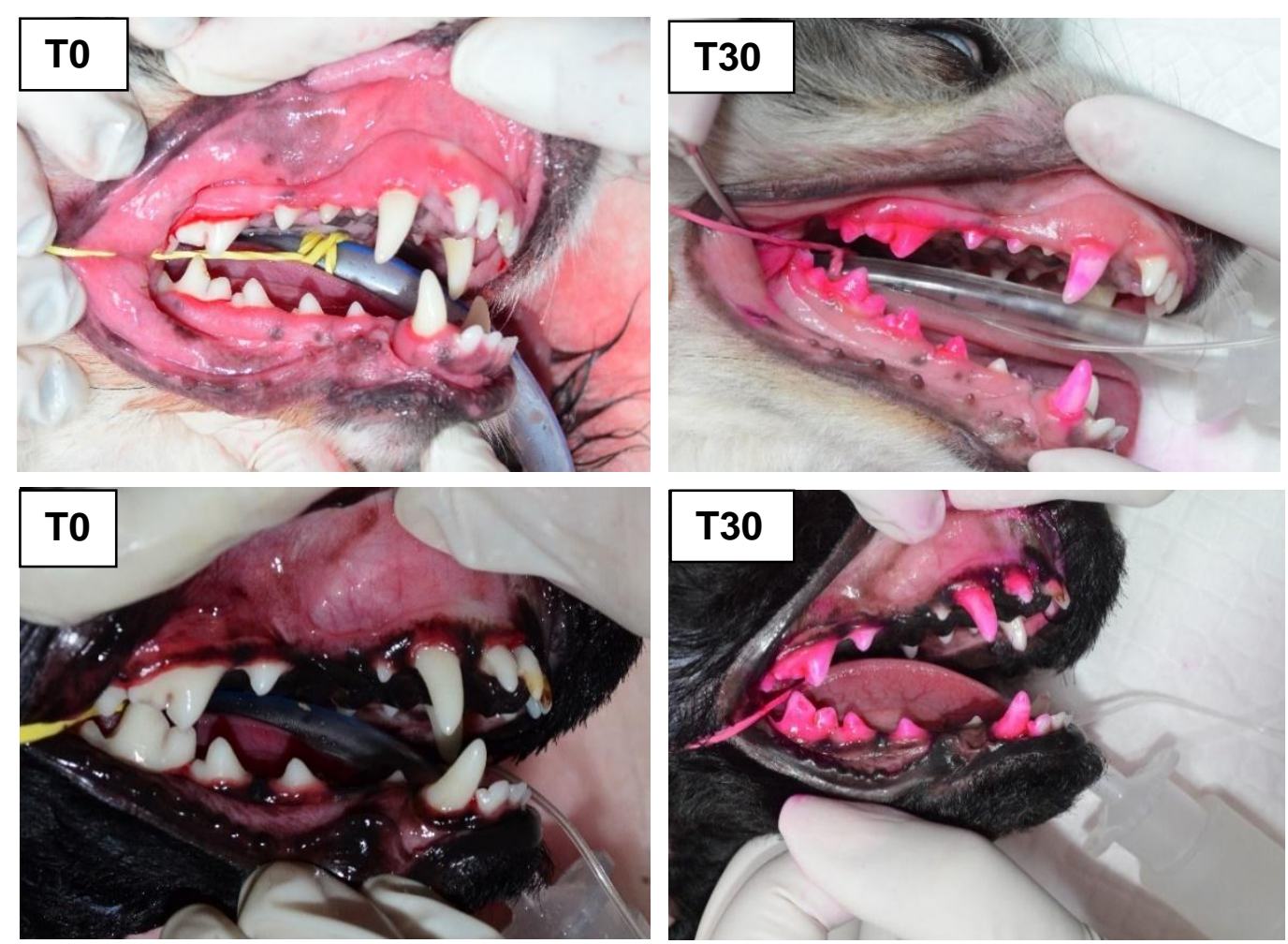

Figura 1. Aspecto fotográfico do antes (T0) e depois (T30) de cães do Grupo Controle (CTL). 

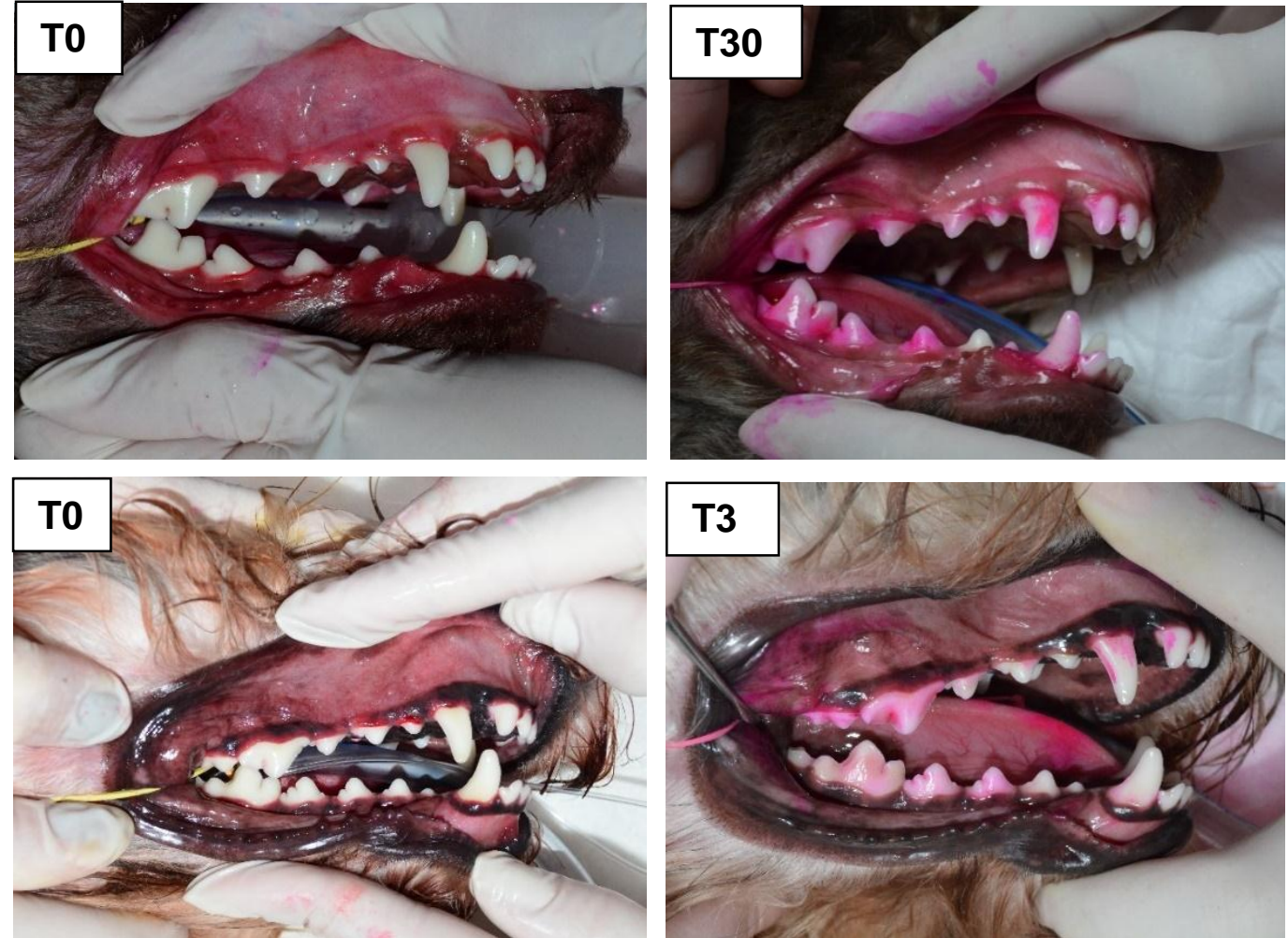

Figura 2. Aspecto fotográfico do antes (T0) e depois (T30) de cães do grupo Espuma Bucal Ibasa.

Tabela 2. Escores de acúmulo de placa bacteriana (média \pm desvio padrão) conforme metodologia de Logan \& Boyce em cães do grupo controle e espuma bucal.

\begin{tabular}{|c|c|c|c|c|}
\hline \multirow{2}{*}{$\begin{array}{c}\text { Grupo/ } \\
\text { Dentes avaliados }\end{array}$} & $\begin{array}{l}\text { Controle } \\
\text { (CTL) }\end{array}$ & $\begin{array}{l}\text { Espuma Bucal } \\
\text { (EB) }\end{array}$ & \multirow[t]{2}{*}{ \% Diferença } & \multirow[t]{2}{*}{ P-value } \\
\hline & \multicolumn{2}{|c|}{ Média \pm Desvio Padrão } & & \\
\hline Incisivos e Caninos & $2,45 \pm 0,92$ & $1,18 \pm 0,66$ & 52 & 0,04 \\
\hline Pré-molares e Molares & $3,08 \pm 1,24$ & $3,32 \pm 1,31$ & . & 0,85 \\
\hline Maxila & $3,36 \pm 1,17$ & $3,20 \pm 1,37$ & 5 & 0,99 \\
\hline Mandíbula & $2,14 \pm 0,54$ & $1,79 \pm 0,58$ & 16 & 0,39 \\
\hline Lado Esquerdo & $2,67 \pm 0,84$ & $2,25 \pm 0,34$ & 16 & 0,78 \\
\hline Lado Direito & $2,96 \pm 1,34$ & $2,90 \pm 1,11$ & 2 & 0,92 \\
\hline
\end{tabular}

Os cães têm o uso dos seus dentes mais especializado do que humanos, os incisivos são usados para rasgar, caninos para prender e pré-molares e molares para cortar e triturar. Devido a estas específicas funções, formato e oclusão destes dentes e relativamente pequeno tamanho do alimento, a mastigação em carnívoros domésticos é limitada a cortar e triturar, funções que envolvem os dentes caudais (14). Por isso, a redução do IPB nos dentes incisivos e caninos é de extrema importância.

Em razão da espuma bucal não realizar uma ação mecânica nos dentes, não foi observada diferença significativa entre os tratamentos nos dentes pré-molares e molares. Telhado et al. (26), estudando cães da raça Pastor Alemão, observaram que os quartos pré- 
molares e os primeiros pré-molares foram acometidos por DP de forma intensa. Quando se espera redução do depósito dental somente por meio de agente mecânico, a inclusão de todos os dentes poderia ser duvidosa, pois dentes que não são envolvidos no trituramento do alimento (incisivos, caninos e pequenos pré-molares) mostrariam perda significante de depósitos dentais $(14,27)$.

Em contrapartida, a Espuma Bucal tem seu mecanismo baseado na fricção da língua sobre os dentes e gengiva do animal após a aplicação. Por isso, a Espuma Bucal IBASA ${ }^{\circledR}$ é indicada como higienizante devido à sua capacidade de controlar os micro-organismos presentes na cavidade bucal, por apresentar um pH compatível com o da saliva e por conter em sua formulação pirofosfato de sódio, tintura de própolis, essência de menta e lauril sulfato de sódio (28).

Estudos clínicos demonstram que a utilização de dentifrícios a base de pirofosfato resultam na estabilização das fases precursoras de calcificação da $\mathrm{PB}$, pois o pirofosfato se une aos cristais de cálcio, inibindo a deposição nas superfícies dentais e a formação do cálculo dentário (o cálcio se une ao fosfato de cálcio presente na saliva, inibindo a formação de novos cristais), sendo assim o cálculo formado será mais poroso, facilitando sua remoção $(29,30)$. Este efeito foi demonstrado em estudo para avaliar o efeito de um biscoito extrusado com cobertura de pirofosfato de sódio sobre o cálculo e placa dentária pré-existentes em cães após 4 semanas, observou-se uma redução de 4,5\% do IPB foi verificada no grupo teste, enquanto no grupo controle houve um aumento de $10,8 \%$ (31).

De acordo com Abdalla (14), os dentes maxilares são mais acometidos por PB e cálculo quando comparado com os mandibulares. No presente estudo, houve uma redução do IPB nos dentes maxilares $(3,36 \pm 1,17$ (CTL) vs 3,20 $\pm 1,37$ (EB) $(p=0,99))$ e nos mandibulares $(2,14 \pm 0,54$ (CTL) vs 1,79 $\pm 0,58$ (EB) $(p=0,39)$ ), fato também relatado por Telhado et al. (26), Hennet et al. (27) e Rosemberg et al. (32). Com relação a diferença entre o lado dos dentes, foi observado uma redução (16 e $2 \%$, respectivamente) do índice de placa em cães que receberam Espuma Bucal quando comparados ao grupo controle, avaliando-se os dentes do lado esquerdo $(2,67 \pm 0,84$ (CTL) vs 2,25 $\pm 0,34$ (EB) $(p=0.78)$ ) como os do lado direito

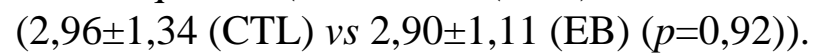

Em razão da $\mathrm{PB}$ ser considerada o gatilho para a instalação de periodontopatias como a DP $(14,33)$, a avaliação dos IPB é essencial em estudos com produtos destinados a reduzir o acúmulo de PB. Neste estudo observamos que os animais que utilizaram a Espuma Bucal durante 30 dias mostraram 52\% a menos no IPB nos dentes incisivos e caninos. Além disso, observamos uma redução dos índices de placa em cães que receberam Espuma Bucal quando avaliados os dentes do lado esquerdo, direito, maxilares e mandibulares, o que demonstra a contribuição deste produto na redução do acúmulo de $\mathrm{PB}$ na boca de cães tratados profilaticamente.

\section{CONCLUSÕES}

A Espuma Bucal IBASA ${ }^{\circledR}$ demonstrou ser eficaz na promoção da saúde oral de cães, pois, auxilia na manutenção da saúde bucal de dentes e gengivas dos animais, controlando a proliferação dos micro-organismos causadores da DP.

\section{REFERÊNCIAS}


1. Van Der Broek AM, Feenstra L, De Baat C. A review of the current literature on etiology and measurements methods of halitosis. J Dent. 2007;35(8):627-35. doi: https://doi.org/10.1016/j.jdent.2007.04.009.

2. Gouveia AIEA. Doença periodontal no cão [dissertação] [Internet]. Lisboa: Universidade de Lisboa; 2009 [cited 2019 Jul 10]. Available from: http://hdl.handle.net/10400.5/1677

3. Harvey CE. Periodontal disease in dogs: etiopathogenesis, prevalence, and significance. Vet Clin North Am Small Anim Pract. 1998;28(5):1111-227. doi: https://doi.org/10.1016/S0195-5616(98)50105-2.

4. Rezende RJ, Carneiro e Silva FO, Milken VNF, Lima CAP, Lima TBF. Frequência de placa bacteriana dental em cães. Bioscience. 2004;20(2):113-8.

5. Hale FA. The owner-animal-environment triad in the treatment of canine periodontal disease. J Vet Dent. 2003;20(2):118-22. doi: https://doi.org/10.1177/089875640302000206.

6. Duboc MV. Percepção de proprietários de cães e gatos sobre a higiene oral de seu animal [dissertação] [Internet]. Seropética: Universidade Federal Rural do Rio de Janeiro; 2009 [cited 2019 Jul 10]. Available from: https://tede.ufrrj.br/jspui/handle/tede/787

7. Pavlica Z, Petelin M, Juntes P, Erzen D, Crossley DA, Skaleric U. Periodontal disease burden and pathogenic changes in organs of dogs. J Vet Dent. 2008;25(2):97-105. doi: https://doi.org/10.1177/089875640802500210.

8. Santos JDMMP. Relação entre a doença periodontal e doenças sistêmicas bacterianas no cão: um estudo retrospectivo [dissertação] [Internet]. Lisboa: Universidade de Lisboa; 2018 [cited 2019 Jul 10]. Available from: http://hdl.handle.net/10400.5/15825

9. World Small Animal Veterinary Association - WSAVA. Global dental guidelines [Internet]. Ontario: WSAVA; 2018 [cited 27 Oct 2018]. Available from: https://wsava.org/

10. Lindhe J, Hamp S, Löe H. Plaque induced periodontal disease in beagle dogs: a 4-year clinical, roentgenographical and histometrical study. J Periodontal Res. 1975;10(5):24355. doi: https://doi.org/10.1111/j.1600-0765.1975.tb00031.x.

11. Quirynen M, Teughels W, Haake S, Newman MG. Microbiology of periodontal diseases. In: Carranza FA, Newman MG, Takei HH, Klokkevold PR. Carranza's clinical periodontology. St. Louis: WB Saunders; 2006. p. 134-69.

12. Neves IML. Estudo da relação entre o diagnóstico clínico e radiográfico de doença dentária no gato [dissertação] [Internet]. Lisboa: Universidade Lusófona de Humanidades e Tecnologias; 2018 [cited 27 Oct 2019]. Available from: http://hdl.handle.net/10437/8769

13. Gioso MA. Odontologia veterinária para o clínico de pequenos animais. 2a ed. São Paulo: Manole; 2007. 
14. Abdalla SL. Análise computadorizada para avaliação dos índices de placa bacteriana e cálculo dentário em cães (Canis familiaris) [dissertação] [Internet]. Seropédica: Universidade Federal Rural do Rio de Janeiro; 2008 [cited 27 Oct 2018]. Available from: https://tede.ufrrj.br/jspui/handle/tede/892

15. Niemiec B. Periodontal disease and periodontal treatment. Top Companion Anim Med. 2008;23(2):72-90.

16. Carreira LM, Dias D, Azevedo P. Serum ionized calcium quantification for staging canine periodontal disease: a preliminary study. Top Companion Anim Med. 2015;30(2):48-50. doi: https://doi.org/10.1053/j.tcam.2015.07.002.

17. Harvey CE. Management of periodontal disease: understanding the options. Vet Clin North Am Small Anim Pract. 2005;35(4):P819-36. doi: https://doi.org/10.1016/j.cvsm.2005.03.002.

18. Wink FC. Doença periodontal em cães [trabalho de conclusão de curso] [Internet]. Porto Alegre: Universidade Federal do Rio Grande do Sul; 2017 [cited 24 Jul 2018]. Available from: http://hdl.handle.net/10183/170536

19. Harvey CE, Emily PP. Small animal dentistry. St Louis: Mosby; 1993.

20. Marshall M, Wallis C, Milella L, Colyer A, Tweedie A, Harris S. A longitudinal assessment of periodontal disease in 52 miniature schnauzers. BMC Vet Res. 2014;10(166):1-13. doi: https://doi.org/10.1186/1746-6148-10-166.

21. Hamp SE, Olsoon SE, Farso-Madsen K, Viklands P. A Macroscopic and radiologic investigation of dental diseases of the dog. Vet Radiol. 1984;25(2):86-92. doi: https://doi.org/10.1111/j.1740-8261.1984.tb01916.x.

22. Gorrel C. Home care: products and techniques. Clin Tech Small Anim Pract. 2000;15(4):226-31. doi: https://doi.org/10.1053/svms.2000.21625.

23. Rawlings JM, Grrel C, Markwell PJ. Effect on canine oral health of adding chlorhexidine to a dental hygiene chew. J Vet Dent. 1998;15(3):129-34. doi: https://doi.org/10.1177/089875649801500303.

24. Veterinary Oral Health Council - VOHC [Internet]. Meridian: VOHC; 2018 [cited 2018 Oct 10]. Available from: http://www.vohc.org/

25. Logan EI, Boyce EN. Oral health assessment in dogs: parameters and methods. J Vet Dent. 1994;11(2):58-63.

26. Telhado JP, Maganin JR, Diele CA, Marinho MS. Incidência de cálculo dentário e doença periodontal em cães da raça pastor alemão. Cienc Anim Bras. 2004;5(2):99-104.

27. Hennet P, Servet E, Venet C. Effectiveness of an oral hygiene chew to reduce dental deposits in small breed dogs. J Vet Dent. 2006;23(1):6-12. doi: https://doi.org/10.1177/089875640602300101. 
28. IBASA. Relatório técnico da espuma bucal Ibasa [Internet]. Porto Alegre: IBASA; 2018 [cited 2018 Mar 23]. Available from: https://www.ibasa.com.br/

29. Hoffmann CH. Dentifrícios em periodontia [trabalho de conclusão de curso]. Florianópolis: Universidade Federal de Santa Catarina; 2008 [cited 2018 Mar 23]. Available from: http://tcc.bu.ufsc.br/Espodonto281462.PDF

30. Ferreira DG. Dentifrícios Branqueadores: composição, efeitos, eficácia e cosméticos de venda livre em Portugal [dissertação] [Internet]. Porto: Universidade Fernando Pessoa; 2017 [cited 2018 Mar 23]. Available from: http://hdl.handle.net/10284/6541

31. Carciofi AC, Bazolli RS, Barbudo GR, Zanni A, Carvalho AZ. Efeito de um biscoito extrusado com cobertura de pirofosfato de sódio sobre o cálculo e a placa dentária préexistentes em cães. Ars Vet. 2007;23(1):47-53. doi: http://dx.doi.org/10.15361/21750106.2007v23n1p47-53.

32. Rosemberg HM, Rehfeld CE, Emmering TE. A method for the epidemiologic assessment of periodontal health disease in a Beagle Hound colony. J Periodontol. 1966;37(3):20813. doi: https://doi.org/10.1902/jop.1966.37.3.208.

33. Loesche WJ. Cárie dental: uma infecção tratável. Rio de Janeiro: Cultura Médica; 1993.

Recebido em: 17/07/2020

Aceito em: 07/12/2020 